\title{
Modeling of Wood Gasification in an Atmospheric CFB Plant
}

\author{
Erik Dahlquist ${ }^{1}$, Muhammad Naqvi ${ }^{1}$, Eva Thorin ${ }^{1}$, Jinyue Yan $^{1}$, Konstantinos Kyprianidis ${ }^{1}$, Philip \\ Hartwell $^{2}$ \\ ${ }^{1}$ School of Sustainable Development of Society and Technology, Mälardalen University (MDH), Sweden, \\ \{erik.dahlquist, raza.naqvi, eva.thorin, jinyue.yan, \\ konstantinos.kyprianidis\} @mdh.se \\ ${ }^{2}$ BioRegional MiniMills (UK) Ltd., United Kingdom
}

\begin{abstract}
The energy situation in both process industries and power plants is changing and it is of interest to investigate new polygeneration solutions combining production of chemicals with the production of power and heat. Examples of such chemicals are methane, hydrogen, and methanol etc. Integration of gasification into chemical recovery systems in the pulp and paper production systems and into the combined heat and power (CHP) systems in power plant applications are among the possible polygeneration systems. It is also interesting to look at the potential to introduce combined cycles with gas turbines and steam turbines as a complement. To perform such analysis, it is important to have relevant input data on what gas composition we can expect from running different type of feed stock. In this paper, we focus on the wood pellets. Experimental results are correlated into partial least squares models to predict major composition of the synthesis gas produced under different operating conditions. The quality prediction models then are combined with physical models using Modelica for investigation of dynamic energy and material balances for large plants. The data can also be used as input to analysis using e.g. ASPEN plus and similar system analysis tools.
\end{abstract}

Keywords: wood pellets, gasification, CHP, Modelica, methane, hydrogen

\section{Introduction and Literature Review}

In the following section, short style guidelines are given. In this paper modeling of biomass gasification systems is discussed especially the approach based on energy and mass balances in combination with partial least square (PLS) models developed from experimental results. Dipal and Baruah (2014) made an overview of biomass gasification modelling. Different modeling approaches were categorized based on criteria such as type of gasifier, feedstock, modeling considerations and evaluated parameters. Gómez-Barea and Leckner (2010) structured the modeling work performed with approaches, from artificial neural nets to computational fluid dynamics. The study covered the conversion of fuel particles, char, and the gas and concluded that most of the different approaches fit quite well between models and the experimental results. However, there are research knowledge gaps exist in case of real gasifiers or systems at a large scale. Capata and Veroli (2012) made a mathematical model over an air-blown a circulating fluidized bed (CFB) gasifier with a capacity of $100 \mathrm{kWth}$ range. The study concluded that there were some problems to get reasonable predictions of tar formation. It is interesting to note that we did not create any detectable amounts of tar when we were running our CFB gasifier with a capacity of 100-200 kWth with the wood pellets. This shows that the type of fuel and plant operating conditions affect the gasification results. It becomes difficult to obtain accurate models correlating to the experiments unless the mechanisms are not completely understood. Blasi (2015) has made an overview of the kinetic processes in detail to describe tar formation from a theoretical perspective. Still, it is important to describe what is actually taking place inside the reactors to be able to predict the process.

\section{Description of the Pilot Plant}

The experimental work has been performed in a pilot plant at Bioregional mini-mills in Manchester. The CFB reactor is heated with a combustor, which is shut off when the operating temperature is achieved. The pressurized air is heated in an electric heater to the desired operating temperature. The gas produced in the CFB is cleaned in two ceramic filters in parallel followed by a scrubber. The gas analysis is performed using an ABB gas chromatograph (GC). The gas is extracted continuously and a new sample is introduced to the GC approximately every five minutes. The plant lay out is shown in Fig. 1 that includes the gasifier, cyclone, gas filtration unit, biomass feeder, hot gas generator and the GC.

In Table 1, we have presented the experimental results from the pilot plant. The feed rate is in ton DS/h.m² based on the reactor size. The relative oxidation (Relox) means the amount of air $\left(\mathrm{m}^{3}\right)$ needed for the $100 \%$ oxidation of $1 \mathrm{~kg}$ of fuel (dried solids). 


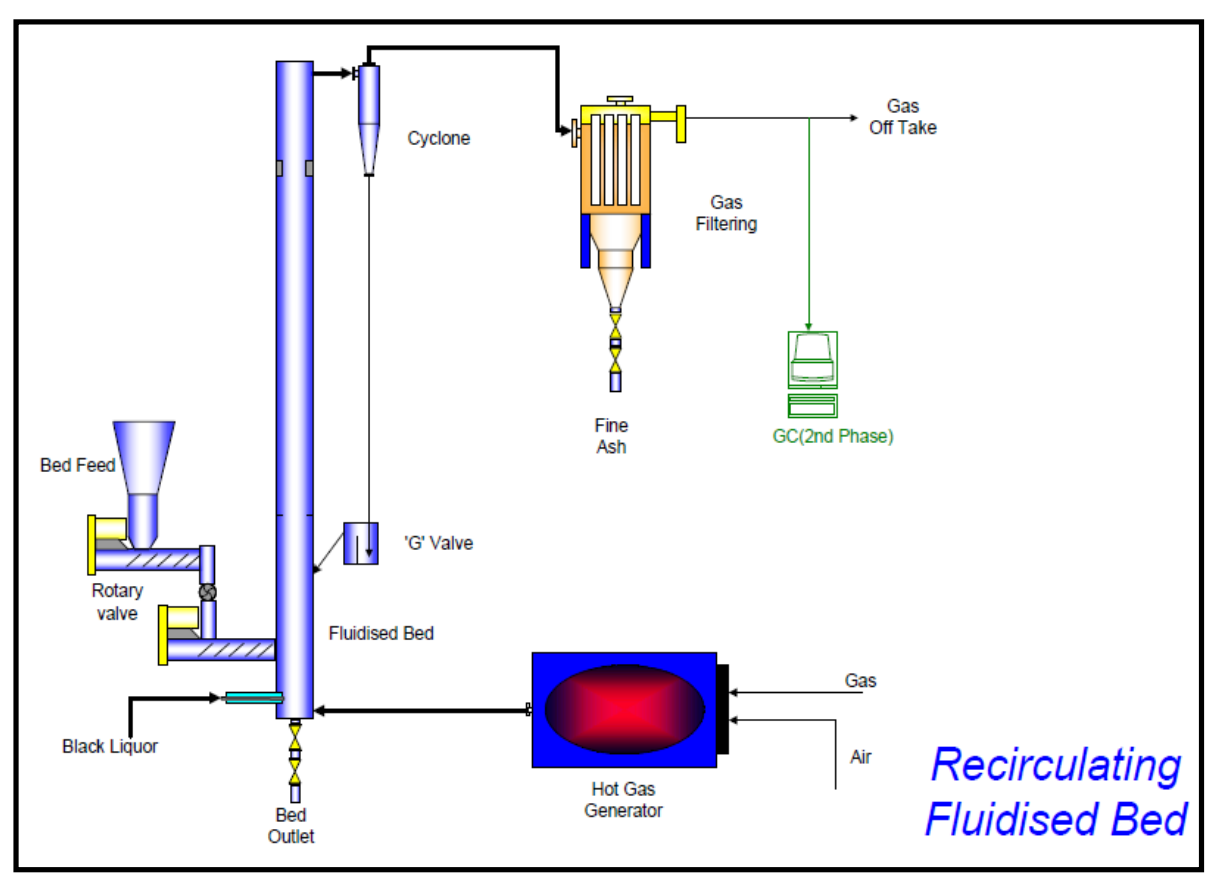

Figure 1. Schematic illustration of the CFB gasifier

Table 1. Results from experiments with wood pellet operations

\begin{tabular}{|l|l|l|l|l|l|l|l|}
\hline $\begin{array}{l}\text { Avg. } \\
\text { Temp, } \\
\text { T }\end{array}$ & $\begin{array}{l}\text { Fuel } \\
\text { feed, FF }\end{array}$ & $\begin{array}{l}\text { Relox, } \\
\text { RE }\end{array}$ & $\mathbf{M C}$ & $\mathbf{C O}$ & $\mathbf{H}_{\mathbf{2}}$ & $\mathbf{C O}_{2}$ & $\mathbf{C H}_{\mathbf{4}}$ \\
\hline T2-T6 & tDS/h.m $\mathrm{m}^{2}$ & & & $\%$ & $\%$ & $\%$ & $\%$ \\
\hline 700.6 & 1.07 & 0.36 & 0.20 & 8.14 & 5.44 & 15.7 & 0.98 \\
\hline 693.6 & 0.93 & 0.42 & 0.23 & 5.58 & 4.5 & 16.8 & 1.42 \\
\hline 693.6 & 1.02 & 0.38 & 0.35 & 7.43 & 5.78 & 19.7 & 1.32 \\
\hline 718.2 & 1.02 & 0.38 & 0.35 & 6.2 & 2.3 & 15.3 & 1.1 \\
\hline 754.4 & 1.10 & 0.35 & 0.33 & 9.13 & 6.1 & 17.5 & 1.75 \\
\hline 681.8 & 0.79 & 0.49 & 0.41 & 4.67 & 3.51 & 17.2 & 0.61 \\
\hline 737 & 1.02 & 0.38 & 0.40 & 14.1 & 3.56 & 15.5 & 3.06 \\
\hline 774 & 0.85 & 0.46 & 0.44 & 9.75 & 8.51 & 17.2 & 1.99 \\
\hline 800.2 & 0.68 & 0.57 & 0.50 & 10.3 & 8.51 & 18.5 & 1.76 \\
\hline 798.8 & 0.68 & 0.57 & 0.50 & 9.75 & 6.55 & 17.6 & 1.5 \\
\hline 785.8 & 1.01 & 0.38 & 0.40 & 8.82 & 6.38 & 17.4 & 1.31 \\
\hline 809.2 & 1.19 & 0.33 & 0.44 & 7.11 & 4.81 & 16.4 & 1.1 \\
\hline 746.6 & 1.16 & 0.33 & 0.45 & 7.11 & 4.2 & 17.6 & 1.39 \\
\hline 742.6 & 1.11 & 0.35 & 0.46 & 8.8 & 4.02 & 15.6 & 2.77 \\
\hline 762.2 & 1.36 & 0.28 & 0.41 & 11.6 & 4.02 & 14.2 & 3.2 \\
\hline 707.4 & 1.53 & 0.25 & 0.38 & 11.4 & 7.33 & 17.1 & 3.22 \\
\hline 741.4 & 0.85 & 0.46 & 0.44 & 12.1 & 5.4 & 12.1 & 3.36 \\
\hline 702.8 & 1.18 & 0.33 & 0.36 & 9.81 & 7.52 & 16 & 2.19 \\
\hline 671.6 & 1.10 & 0.35 & 0 & 12.5 & 6.47 & 15 & 3.96 \\
\hline
\end{tabular}

In this case, approximately $4.8 \mathrm{~m}^{3}$ of air is needed for the $100 \%$ oxidation of $1 \mathrm{~kg}$ of wood pellets. The moisture content means the moisture including the steam added. The gas composition also includes $\mathrm{N}_{2}$ and $\mathrm{H}_{2} \mathrm{O}$ which is not presented in the table. The amount of tars and higher CHx is excluded since the content is at the detection level, meaning not very accurate values.

\section{Description of Simulation Model Combining Energy and Material Balances with PLS-Models}

The simulation model, used in this paper, is developed in Modelica that can be run in both Dymola and Open Modelica. The model is expressed as a semi-steady state model giving the heat and mass balance of the gasification system. The model consists of a heat and mass balances where material flows as well as molar flows of both organics and inorganics are followed through the system with the gasifier, cyclone, G-valve, heat exchanger/cooler and the scrubber.

The gas composition is given by the PLS-models, determined from experimental measurements, for each of the gas components $\mathrm{H}_{2}, \mathrm{CO}, \mathrm{CO}_{2}$ and $\mathrm{CH}_{4}$, while $\mathrm{N}_{2}$ is assumed as a ballast from the air fed to the system. $\mathrm{H}_{2} \mathrm{O}$ is given by the shift reaction at given conditions and the heat balance of the system based on the partial combustion and the heat losses.

The heating value given for the wood pellets is 18.5 $\mathrm{MJ} / \mathrm{kg}$ which corresponds to the formula $\mathrm{CH}_{2} \mathrm{O}_{1.2}$ at $8 \%$ moisture (measured). For pellets made of wood of spruce and pine, the formula $\mathrm{CH}_{1.44} \mathrm{O}_{0.66}$ (according to the elemental analysis) is expected which corresponds to a higher heating value of $23.7 \mathrm{MJ} / \mathrm{kg}$ and a lower heating value of $21.8 \mathrm{MJ} / \mathrm{kg}$ assuming $8 \%$ moisture. 
Table 2. Polynoms (PLS) for prediction of gas composition as a function of operating conditions with respect to average temperature in the reactor, load, relative oxidation and moisture content

\begin{tabular}{|l|l|l|l|l|l|l|l|}
\hline $\begin{array}{l}\text { Vol } \\
\mathbf{\%}\end{array}$ & $\mathbf{B}_{\mathbf{0}}$ & $\mathbf{A}_{\mathbf{1}}$ & $\mathbf{A}_{\mathbf{2}}$ & $\mathbf{R e l o x}$ & $\begin{array}{l}\mathbf{M C} \\
\mathbf{\%}\end{array}$ & $\mathbf{R}^{2}$ & $\mathbf{Q}^{\mathbf{2}}$ \\
\hline $\mathrm{CO}$ & -12.6 & 0.012 & 8.46 & -0.001 & 0.07 & 0.8 & 0.61 \\
\hline $\mathrm{H}_{2}$ & -13.1 & 0.017 & -0.001 & 0.0472 & 0.07 & 0.8 & 0.57 \\
\hline $\mathrm{CH}_{4}$ & -6.7 & 0.002 & 4.20 & 0.0392 & 0.03 & 0.8 & 0.69 \\
\hline $\mathrm{CO}_{2}$ & 7.2 & 0.020 & 0.00097 & -0.052 & -0.2 & 0.7 & 0.7 \\
\hline
\end{tabular}

According to the actual chemical analysis of the wood pellets, $\mathrm{CH}_{1.46} \mathrm{O}_{0.625}$, the $100 \%$ oxidation demand of air would in this case be $4.8 \mathrm{~nm}^{3} / \mathrm{kg}$ DS, for the two compositions. In the calculation for $100 \%$ relox in this study the latter value has been used for the wood pellets. All five measured major gas components are correlated to the relox, capacity, $\mathrm{MC}$ and the average temperature in the CFB using PLS regression. The results are shown in Table 2. The gas composition, $\mathrm{C}$ (vol.\%) is calculated for these six major gas components with a polynom as shown in

$$
\mathrm{C}=\mathrm{B}_{0}+\mathrm{A}_{1} \cdot \mathrm{T}+\mathrm{A}_{2} \cdot \mathrm{FF}+\mathrm{A}_{3} \cdot \mathrm{RE}+\mathrm{A}_{4} \cdot \mathrm{MC}
$$

where $\mathrm{T}$ is the value of the average temperature in o $\mathrm{C}$ of the five positions in the reactor, FF is the load in ton dry solids per $\mathrm{m}^{2}$ of the reactor cross area per hour, RE is the relative oxidation as the percentage of oxygen in relation to what is needed for $100 \%$ oxidation of all organic material and $\mathrm{MC}$ is the moisture content in $\%$ of the total fuel weight including the added steam. $\mathrm{B}_{0}, \mathrm{~A}_{1}$, $A_{2}, A_{3}$ and $A_{4}$ are the regression constants given in the Table 2.

$\mathrm{R}^{2}$ is 1.0 when perfect fit of all experimental data into the model, while 0.5 is a value that is a minimum for being able to start using the correlation. $\mathrm{Q}^{2}$ is the corresponding prediction power when the model is used to predict performance at any condition covered by the experiments. Above 0.5 we can start using the prediction model and the prediction is perfect at 1.0. Here we get 0.6-0.7 for most of the gas components, which makes the models usable, although quite a bit from very good. The moisture $\left(\mathrm{H}_{2} \mathrm{O}\right)$ is calculated from the shift reaction with the constant KT given for the average temperature $(\mathrm{T})$, assuming we have steady state conditions as shown in

$$
\begin{aligned}
& \mathrm{K}_{\mathrm{T}}=[\mathrm{CO}]\left[\mathrm{H}_{2} \mathrm{O}\right] /\left[\mathrm{H}_{2}\right]\left[\mathrm{CO}_{2}\right] \\
& \mathrm{K}_{\mathrm{T}}=(\text { Temp-649)*(0.154/55)+0.50800 }
\end{aligned}
$$

This is for the actual gasification. For the moisture content in the gas after the scrubber, the water content of the gas at saturation for the given scrubber temperature is used. From this we recalculate the gas composition used in the simulations later on as a function of operating conditions, but then combining also with energy and mass balances. The results from the combined model for wood pellets are presented in Table 3. The composition of wood pellets is assumed as $\mathrm{CH}_{1.44} \mathrm{O}_{0.66}$ with $\mathrm{Mw}$ of 24 . We need to add net $42.9 \mathrm{~mol}$ $\mathrm{O}_{2} / \mathrm{kg}$ fuel and $3.76 \mathrm{~mol} \mathrm{~N}_{2}$ per mol $\mathrm{O}_{2}$ added as air for $100 \%$ oxidation.

The relative oxidation and the load has strong impact while the temperature has less effect. However, the steam has no significant impact, i.e. when increasing by $40 \%$ from a relatively high level. In the reactor, it is seen that the heat demand for driving the processes varies considerably, i.e. from $30 \%$ to about $50 \%$.

It is interesting to note that we cannot detect any tars in the synthesis gas, neither directly at the fuel injection point ( 2 meters above the injection point) or in the exhaust gas channel before the filter.

\begin{tabular}{|c|c|c|c|c|c|c|c|c|c|c|}
\hline Load & Relox & MC & $\mathbf{T}$ & $\mathrm{CO}$ & $\mathbf{H}_{2}$ & $\mathrm{CH}_{4}$ & $\mathrm{CO}_{2}$ & $\mathbf{N}_{2}$ & $\mathrm{H}_{2} \mathrm{O}$ & HHV \\
\hline$t / m^{2} \cdot h$ & $\%$ & $\%$ & ${ }^{\circ} \mathrm{C}$ & $\%$ & $\%$ & $\%$ & $\%$ & $\%$ & $\%$ & $\mathrm{~kJ} / \mathrm{m}^{3}$ \\
\hline 1 & 35 & 30 & 700 & 8.4 & 20 & 1.8 & 17.6 & 37.6 & 14.6 & 3918 \\
\hline 1 & 25 & 30 & 700 & 9.5 & 22.7 & 1.4 & 20.6 & 30.5 & 15.2 & 4221 \\
\hline 1 & 45 & 30 & 700 & 7.5 & 17.8 & 2 & 15.2 & 43.2 & 14.2 & 3681 \\
\hline 1 & 35 & 45 & 700 & 10.5 & 20.2 & 2.5 & 15.1 & 38 & 13.7 & 4498 \\
\hline 1 & 35 & 30 & 800 & 8.5 & 19.7 & 1.8 & 17.2 & 37.1 & 15.8 & 3898 \\
\hline 2 & 35 & 30 & 700 & 12.4 & 20.4 & 4.6 & 11.4 & 38.4 & 12.9 & 5565 \\
\hline 2 & 25 & 30 & 700 & 14 & 23.3 & 4.8 & 13.4 & 31.3 & 13.2 & 6191 \\
\hline 2 & 45 & 30 & 700 & 11 & 18.2 & 4.4 & 9.8 & 43.9 & 12.7 & 5078 \\
\hline 2 & 35 & 45 & 700 & 13.8 & 20.5 & 5.2 & 9.4 & 38.5 & 12.6 & 5993 \\
\hline 2 & 35 & 30 & 800 & 12 & 20.2 & 4.3 & 11.8 & 38.1 & 13.6 & 5398 \\
\hline
\end{tabular}

Table 3. Results from simulation using the combined modelica and PLS models for gas after condensation to $40^{\circ} \mathrm{C}$ for wood pellets. MC is moisture content in pellet + steam 
The bed weight is ca $21 \mathrm{~kg}$. $2 * 0.4 \mathrm{~kg}$ is passing over to the filter and the filter ash has $7 \%$ respectively $6.2 \%$ $\mathrm{C}$ in the ash. The carbon particles are small balls and when the bed material is emptied, the $\mathrm{C}$-content is found to be $1.2 \%$. The total carbon in the feed is $62 \mathrm{~kg}$ and in the residue, is $0.3 \mathrm{~kg}$. The $\mathrm{C}$-conversion is $(1-0.3 / 62)=$ $99.5 \%$. We have now been running the experiments five times and tried to control the process in order to verify that no detectable tars are formed and now feel quite convinced that this is a fact. We also have ideas about the reasons for no tar in the gas and will perform tests in future to confirm this experimentally.

\section{System Studies}

The studies on $\mathrm{H}_{2}$-production in a $\mathrm{CHP}$ plant was presented (Naqvi et al. 2016, 2017). Yang and Ogden (2007) made an overview of production costs for Hydrogen production. Further studies were made on black liquor gasification systems where different cycles and solutions were compared, including among others $\mathrm{CO}_{2}$ removal (Naqvi et al. 2010, 2017). Asadullah (2014) has made a critical review of down- stream gas cleaning after biomass separation, which includes also particle and tar removal. Concerning the gas separation, $\mathrm{H}_{2}$ is a very small molecule and thus passes through even tight membranes quite easily compared to most other molecules except water.

By condensing water before the membrane unit, we thus can get relatively pure $\mathrm{H}_{2}$ in the permeate. The separation between $\mathrm{N}_{2}$ and $\mathrm{H}_{2}$ has been commercialized since long ago in the ammonia production. Here relatively large pressure difference between feed and permeate has been applied. Now new membranes are coming where the pressure difference might be only one or a few bars, which makes it easier from a system perspective. Example of such membranes are porous graphene (Du et al., 2011) and PDMS composites with $\mathrm{SiO}_{2}$ and $\mathrm{B}_{2} \mathrm{O}_{3}$ (Lee et al., 2015). If we can let $\mathrm{H}_{2}$ pass through while the rest are remaining in the reject, these can be combusted in a boiler or even a gas turbine with an external combustion chamber. If we want to upgrade the gas further $\mathrm{CO}_{2}$ is the second easiest gas to separate as it is quite polar and thereby can be dissolved in liquids like MEA (mono ethanol amine) or alkaline solutions like the scrubber solution used to separate $\mathrm{H}_{2} \mathrm{~S}$ in the black liquor process, but with a higher $\mathrm{pH}$. With $\mathrm{pH} 11.5$ all $\mathrm{CO}_{2}$ is absorbed. With the MEA it is easy to regenerate the liquid by just heating and stripping off $\mathrm{CO}_{2}$ again. Using alkaline solution, the $\mathrm{Na}_{2} \mathrm{O}$. $\mathrm{TiO}_{2}$ regeneration can be used, but a bit more complex system solution is needed. The separation with MEA using micro porous membranes was demonstrated by Yuexia et al. (2010) and Lv et al. (2012). Here modification of the polypropylene membrane was made to get long term stabile performance.

In the solution presented in Figure 2, we have a gasification process that is used for the production $\mathrm{CH}_{4}$. The synthesis gas could be separated to extract methane, while the residual gas could be combusted directly in a boiler, or in an external gas turbine combustor, making a combined cycle possible. The heat from the steam turbine condenser then could be used for the district heating. Even $\mathrm{CO}_{2}$ can be removed at the far end of the exhaust gas train.

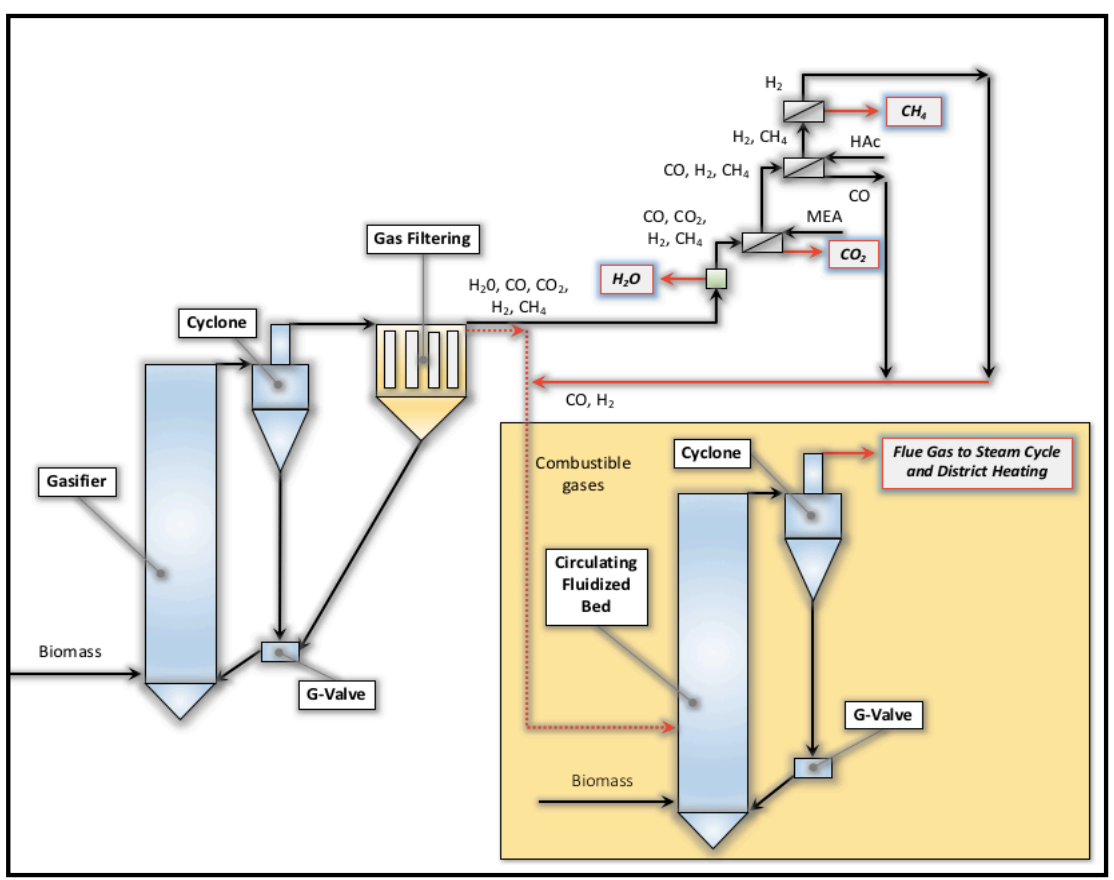

Figure 2. Different bio-refinery systems can be either integrated or operated separately 
In a system for black liquor gasification, an alternative with a combi-cycle turned out to be able to give an electric to fuel heating value efficiency of up to $38 \%$, which is high for a process with such a poor fuel (Dahlquist, Jones 2005). If we instead look at alternatives with biomass in a CHP plant, the district heating is very interesting from an energy efficiency perspective but with an issue that the heat demand varies significantly over the year. It is thus interesting to be flexible such as the heat demand must be fulfilled when it is very cold, and then chemicals or electric power may be of secondary importance. As the conditions will vary much more than previously, the dynamics of the system is of interest in order to perform transition from one operation mode to another in a smooth way. This is another important aspect needing the dynamic simulation models like the one in Modelica, and not only steady state models.

In the future, we see a stronger demand to use cheaper fuels in the CHP plants, as the cost for biomass fuels like pellets becomes too high to be competitive in many cases. Organic waste then is interesting as the cost is very low or you even get paid to take care of the waste. By gasifying the waste, remove the particles like alkali salts and corrosive substances like $\mathrm{HCl}$, we can produce clean fuel that can be used in both gas turbines and boilers that are not designed for wastes. The waste has not been directly tested in the pilot plant but should be principally easier than the black liquors that we actually have tested and found feasible to use as fuel.

Concerning the gas separation using membrane filtration, the plan is to test the separating gas compositions that are produced from the gasifier, to determine the efficiency for the mixtures. There are new types of membranes are developed all which gives a high probability for finding suitable membranes to use in the future, and also to give input to membrane developers what to aim for? The regeneration of absorbents used in the liquid-membrane-combinations is another task to develop further. Here the possibility to recover $\mathrm{CO}_{2}$ and deposit or use it for other purposes is of high potential interest to reduce $\mathrm{CO}_{2}$ emissions to the atmosphere. This also should have a positive economic impact in the future.

\section{Conclusions}

In the paper, we have shown how regression models like PLS, PCA and similar can be made from experiments and combined with the dynamic physical models developed in the Modelica. These models can be used to study different systems from the energy and material balance perspective, but also to investigate how to switch from one process mode to another in a smooth way. This has significance as the economic conditions will vary considerably in the future from one time of the day to another, as well as over the season, making it much more complex to fulfil different demands. When there is focus on the conversion processes such as the gasification, we will see an increasing demand for the gas separation, like membrane separation, for developing efficient system solutions. The new demands like $\mathrm{CO}_{2}$ removal may give different economical optima, if $\mathrm{CO}_{2}$ is valued significantly higher than today. This will also shift the use of fossil fuels for production of chemicals into a demand to use biomass, which will give new incentives to the proposed processes for production of base chemicals like $\mathrm{CH}_{4}$ and $\mathrm{H}_{2}$.

\section{Acknowledgements}

We thank Bioregional and especially Sue Riddlestone, for making their pilot plant available for the tests with wood pellets, and Swedish Energy Agency and KKS are acknowledged for the financial support.

\section{References}

A. Gómez-Barea and B. Leckner. Modeling of biomass gasification in fluidized bed, Progress in Energy and Combustion Science, 36(4): 444-509, 2010.

C. D. Blasi. Kinetic modeling of biomass gasification and combustion, Intelligent Energy Europe (PyNe). (downloaded 5 Jan, 2016).

C. Roberto and M. D. Veroli. Mathematical Modelling of Biomass Gasification in a Circulating Fluidized Bed CFB Reactor, Journal of Sustainable Bioenergy Systems, 2: 160169, 2012.

C. Yang, and J. Ogden. Determining the lowest-cost hydrogen delivery mode, International Journal of Hydrogen Energy, 32: 268-286, 2007.

D. Baruah and D. C. Baruah. Modeling of biomass gasification: A review, Renewable and Sustainable Energy Reviews, 39: 806-815, 2014.

E. Dahlquist and A. Jones. Presentation of a dry black liquor gasification process with direct caustization, TAPPI Journal: 15-19, 2005.

H. Du, J. Li, J. Zhang, G. Su, X. Li, and Y. Zhao. Separation of Hydrogen and Nitrogen Gases with Porous Graphene Membrane, The Journal of Physical Chemistry, 11: 2326123266, 2011.

L. Yuexia, X. Yua, S. Tu, J. Yan, and E. Dahlquist. Wetting of polypropylene hollow fiber membrane contactors, Journal of Membrane Science, 362: 444-452, 2010.

M. Asadullah. Biomass gasification gas cleaning for downstream applications: A comparative critical review, Renewable and Sustainable Energy Reviews, 40: 118-132, 2014.

M. Naqvi, E. Dahlquist, and J. Yan. Complementing existing CHP plants using biomass for production of hydrogen and burning the residual gas in a CHP boiler, Biofuels, 8(6): 675-683, 2017.

M. Naqvi, J. Yan, M. Danish, U. Farooq, and S. Lu. An experimental study on hydrogen enriched gas with reduced tar formation using pre-treated olivine in dual bed steam gasification of mixed biomass compost, In International Journal of Hydrogen Energy, 41(25): 10608-10618, 2016. 
M. Naqvi, J. Yan, and E. Dahlquist. Synthetic natural gas (SNG) production at pulp mills from a circulating fluidized bed black liquor gasification process with direct causticization, Conference proceedings of ECOS 2010.

M. Naqvi, J. Yan, E. Dahlquist, and S. Naqvi. Off-grid electricity generation using mixed biomass compost: A scenario-based study with sensitivity analysis, Applied Energy, 201: 363-370, 2017.

S. H. Lee and H. K. Lee. Separation of Hydrogen-Nitrogen Gases by $\mathrm{PDMS}_{-} \mathrm{SiO}_{2} \mathrm{~B}_{2} \mathrm{O}_{3}$ Composite Membranes, Membrane Journal 25 (2), 2015.

Y. Lv, X. Yu, J. Jia, S. Tu, J. Yan, and E. Dahlquist. Fabrication and characterization of superhydrophobic polypropylene hollow fiber membranes for carbon dioxide absorption, Applied Energy, 90(1): 167-174, 2012. 